\title{
Morbimortality of hospitalized patients receiving parenteral nutrition and presenting hyponatremia.
}

Gómez Hoyos E1, Matía Martín P², Cuesta Hernández $\mathrm{M}^{2}$, Ortola Buigues $\mathrm{A}^{2}$, Crespo Hernández $\mathrm{I}^{2}$, Pérez Ferre $\mathrm{N}^{2}$, Rubio Herrera MA², De Luis Roman DA1, Calle Pascual A², Runkle de la Vega ${ }^{2}$.

Endocrinology Service. ${ }^{1}$ Clinico Universitario Hospital. Valladolid. ${ }^{2}$ Clinico San Carlos Hospital. Madrid. Spain

\section{INTRODUCTION}

Hyponatremia is the most frequent electrolyte disorder found in clinical practice, and has been associated with increased morbimortalty.

Hyponatremia is even more common among patients receiving parenteral nutricion(PN), a

therapy increasingly in use. However, the morbimortality of hyponatremic patients on PN is unknown

\section{METHODS}

Retrospective study, selecting all patients receiving $P N$ in a teaching hospital from $01 / 11 / 11$ to $01 / 06 / 12$. We evaluated hospital length-of-stay (LOS), in-hospital mortality, serum Sodium ( $\mathrm{SNa}$ ) at admittance, at start and end of PN, and at discharge. Hyponatremia defined as glycemia- corrected

$\mathrm{SNa}<135 \mathrm{mmol} / \mathrm{L}$, triglycerides $<400 \mathrm{mg} / \mathrm{dl}$.

Data analysis: $X^{2}$, T-test, Mann Whitney U, Logistic regression. SPSS 15

\section{RESULTS}

222 patients received PN (57,2\% males). Median age 75 [61-82] years. $14.5 \%$ presented malnutrition (by BMI).

Charlson index was 3.3 (SD 2.4). LOS was 30 [20-40] days. Mortality was $17.7 \% .50 .4 \%(112 / 222)$ presented

hyponatremia in at least one SNa determination, $27 \%$ in at least $25 \%$ of SNas, $15.7 \%$ in at least $50 \%$ of SNas,

and $3 \%$ in at least $75 \%$ of SNa. Mortality rate and LOS $\leq 30$ days distribution depending on the presence of

hyponatremia in the mínimun, 25, 50 and 75 th percentile (P) of all SNa in each patient (Table $n^{0} 1$ and $n^{\circ} 2$ ).

Logistic regression analysis of mortality and LOS $\leq 30$ days depending the presence of hyponatremia in the minimun and 25, 50 and 75 th $\mathrm{P}$ of all SNa in each patient, ajusted by age, gender, Charlson index and BMI (Table $n^{\circ} 3$ and 4$)$.

\begin{tabular}{|c|c|c|c|}
\hline & $\mathbf{n}$ & MORTALITY & p \\
\hline \multicolumn{4}{|c|}{$\mathrm{SNa}_{\text {in }}$ Minimun } \\
\hline$\geq 135$ & 110 & $13(11,8 \%)$ & \\
\hline$<135$ & 112 & $26(23,2 \%)$ & 0,019 \\
\hline \multicolumn{4}{|c|}{$S \mathrm{Na}_{\text {in }} 25$ th $P$} \\
\hline$\geq 135$ & 162 & $27(16,7 \%)$ & \\
\hline$<135$ & 62 & $12(20 \%)$ & 0,346 \\
\hline \multicolumn{4}{|c|}{$\mathrm{SNa}_{\text {in }} 50$ thP } \\
\hline$\geq 135$ & 187 & $30(16 \%)$ & \\
\hline$<135$ & 35 & $9(25,8 \%)$ & 0,129 \\
\hline \multicolumn{4}{|c|}{$\mathrm{SNa}_{\text {in }} 75$ thP } \\
\hline$\geq 135$ & 215 & $36(16,7 \%)$ & \\
\hline$<135$ & 7 & $3(42,9 \%)$ & 0,088 \\
\hline
\end{tabular}

Table $n^{\circ}$ 1: Mortality rate distribution depending on the presence of hyponatremia in the mininum, 25, 50 and $75 \mathrm{Th}$ percentile $(P)$ of all SNa in each patient.

\begin{tabular}{|c|c|c|c|}
\hline $\begin{array}{c}\mathrm{SNa} \\
<135 \mathrm{vs} \geq 135 \mathrm{mmol} / \mathrm{L}\end{array}$ & $\begin{array}{l}\text { ODDS } \\
\text { RATIO }\end{array}$ & IC 95\% & p \\
\hline Minimun & 1,8 & $0,80-4,08$ & 0,154 \\
\hline 25th P & 1,03 & $0,44-2,40$ & 0,946 \\
\hline 50th P & 1,75 & $0,66-4,64$ & 0,257 \\
\hline 75th P & 7,38 & $1,07-50,78$ & 0,042 \\
\hline
\end{tabular}

Table $n^{\circ} 3$. Logistic regression analysis of mortality depending the presence of hyponatremia in the minimun and 25,50 and 75 th $P$ of all $S \mathrm{Na}$ in each patient, ajusted by age, gender, Charlson index and BMI.

\begin{tabular}{|c|c|c|c|}
\cline { 2 - 4 } \multicolumn{1}{l|}{} & $\mathrm{n}$ & LOS $\leq 30$ days & $p$ \\
\hline $\mathrm{SNa}_{\text {in }}$ Minimun & & & \\
\hline$\geq 135$ & 110 & $80(72,7 \%)$ & \\
\hline$<135$ & 112 & $48(42,8 \%)$ & 0,001 \\
\hline $\mathrm{SNa}_{\text {in }} 25 \mathrm{thP}$ & & & \\
\hline$\geq 135$ & 162 & $103(63,9 \%)$ & \\
\hline$<135$ & 60 & $25(41,7 \%)$ & 0,003 \\
\hline $\mathrm{SNa}_{\text {in }} 50$ thP & & & \\
\hline$\geq 135$ & 187 & $114(70 \%)$ & \\
\hline$<135$ & 35 & $14(40 \%)$ & 0,018 \\
\hline $\mathrm{SNa}_{\text {in }} 75 \mathrm{thP}$ & & & \\
\hline$\geq 135$ & 215 & $125(58,1 \%)$ & \\
\hline$<135$ & 7 & $3(42,9 \%)$ & 0,334 \\
\hline
\end{tabular}

Table $n^{\circ} 2$ : LOS $\leq 30$ days distribution depending on the presence of hyponatremia in the mininum, 25, 50 and 75 Th percentile $(P)$ of all NaS in each patient.

\begin{tabular}{|c|c|c|c|}
\hline $\begin{array}{c}\text { SNa } \\
\geq 135 \text { vs }<135 \mathrm{mmol} / \mathrm{L}\end{array}$ & $\begin{array}{c}\text { ODDS } \\
\text { RATIO }\end{array}$ & \multicolumn{1}{c|}{ IC $95 \%$} & $p$ \\
\cline { 2 - 4 } Minimun & 3,86 & $2,03-7,38$ & 0,001 \\
\hline 25th $P$ & 2,73 & $1,43-5,22$ & 0,002 \\
\hline 50th P & 2,78 & $1,22-6,31$ & 0,015 \\
\hline 75th $P$ & 2,6 & $0,44-15,31$ & 0,284 \\
\hline
\end{tabular}

Table $\mathrm{n}^{\circ} \mathbf{4}$. Logistic regression analysis of LOS $\leq 30$ days depending the presence of hyponatremia in the minimun and 25,50 and 75 th $P$ of all $\mathrm{SNa}$ in each patient, ajusted by age, gender, Charlson index and BMI.

\section{CONCLUSIONS}

The presence of sustained hyponatremia is independently associated with increased mortality in patients receiving parenteral nutrition. The absence of hyponatremia is independently associated with a shorter hospital length-of-stay. Hyponatremia should not be overlooked in PN patients. 